\title{
1 Creating movable interfaces by micro-powder injection moulding
}

41 Manufacturing and Materials Department, Cranfield University, Wharley End, Cranfield, Bedfordshire, 5 MK43 0AL, UK.

$6 *$ Corresponding author. Present address: Manufacturing Technology Centre Ltd., Ansty Business Park,

7 Coventry, CV7 9JU, UK. Tel.: +442476701742. E-mail address: usama.attia@the-mtc.org

\section{Abstract}

This paper presents a novel in-situ technique to produce articulated components with high-

11 precision, micro-scale movable interfaces by micro-powder injection moulding ( $\mu \mathrm{PIM})$. The presented process route is based on the use of micro-scale sacrificial layer between the movable subcomponents which is eliminated during the debinding step, creating a dimensionally-controlled, micro-scale mobile interface. The fabrication technique combines the advantages of micro-powder overmoulding, catalytic debinding and sintering. The demonstrated example was a finger bone prosthesis joint consisting of two sub-components with an interface between components of $200 \mu \mathrm{m}$ in size. The geometries of the subcomponents were designed such that they are inseparable throughout the process whilst allowing them to move relative to each other after the debinding stage. The components produced showed the feasibility of the process route to produce readily-assembled meso-, and potentially micro-, scale articulated systems.

Keywords: Micro-powder injection moulding, Metal injection moulding, Micro-cavities, Micro-joints,

Microfabrication, Three-dimensional

\section{Introduction}

Small-scale joints are becoming crucial to the development of the next generation of meso-scale devices. Articulated systems with movable interfaces are particularly important for meso- and micro-scale components. Examples include finger bone replacements, known as phalangeal prostheses, which have component sizes in the order of few millimetres and tolerances in the order of hundreds of microns, such as those tested by Field (2008) and Middleton et al. (2011). Another application for micro-scale 
30 components with moving joins are 'micro-engines', which are micro-scale, power generation devices,

31 currently under consideration as replacements for batteries in consumer portable devices. Typical micro-

32 engines have component sizes in the order of millimetres and tolerances in the order of tens of microns,

33 such as the examples demonstrated by Hassanin and Jiang (2010) and Zhu et al. (2010). 'Micro-

34 manipulators' is another example of micro-scale devices with articulated components, which are used to remove, manipulate or deliver micro-scale elements, for example cells in medical applications, which have different sizes and tolerances in the order of few microns to tens of microns. Kim et al. (2008) have presented demonstrations of such systems.

In spite of the growing applications of metallic components with movable structures, current processing routes pose several constraints on the design and manufacturing routes of such complex structures. Such constraints result in considerable increase in manufacturing time and cost. Whilst fabrication processes for the construction of multiple rigid bodies and their connecting joints - known as kinematic chains - are well characterized at the conventional (macro-) scale, at the micro-scale processes are still in their infancy. This is due to a number of challenges, the most significant of which are: a. limitations on the geometry of fabricable structures, b. material selection limitations, c. assembly challenges, $d$. powder-based fabrication challenges and e. mass manufacturability. In terms of geometry limitations, joints possess usually one, or exceptionally two, degrees of translational or rotational freedom, a limitation imposed by the variants of 'axial' processes (normally lithography or cutting) used in their fabrication. This is evident in the examples available in the literature, such as movable, silicon-based micro-structures produced by Fan et al. (1988) for sensors and actuators, movable microfluidic elements demonstrated by Ling and Lian (2007) using SU-8 fabrication, siliconbased, micro-hinges produced by Pister et al. (1992) and movable micro-gears fabricated from SU-8 by Seidemann et al. (2002). selection. Such structures are severely restricted in terms of possible materials. As illustrated above, materials used for such applications are currently usually either silicon or SU8 (an epoxy-based photoresist). Such materials are notable for their poor wear resistance in moving parts, as illustrated by both Waits et al (2007) and Hergert et al. (2010) in two independent experiments about wear damages induced in micro-scale ball bearings produced by silicon fabrication techniques. 

currently done by post-processing techniques and, therefore, require accurate alignment and tolerance checking. As mentioned above, currently, in-situ alignment has only been achieved with lithographic techniques using materials of limited mechanical performance, notably silicon and SU8. A number of such assembly techniques have been reviewed by Leong et al. (2010) for micro-scale components. For relatively-larger, meso-scale systems, post-processing assembly is usually implemented, such as a pressfit mechanism, as illustrated by Koch and Sandoz (1994) for metal finger joint prosthesis.

To overcome the material and geometrical limitations of silicon and SU8, some recent research has started to investigate the use of powder-based fabrication of micro-scale joints. Additive manufacturing, for example, has been investigated by Yang et al. (2011) for manufacturing conventionally-sized metal joints by laser selective melting. However, the process is comparatively slow and not optimized for micro-scale applications. On the micro-scale, recent work has attempted to produce micro-scale moving joints using powder-based ceramics. The idea was to co-sinter two components made of different materials in order to achieve the clearance required to facilitate motion by difference in volumetric shrinkage of the two materials. Demonstrations have been made by Piotter et al. (2010a and 2010b) and Ruh et al. (2008 and 2010) using powder injection moulding. Such a procedure requires careful adjustment of process conditions to achieve the exact shrinkage in subcomponents, such that a movable clearance is achieved. obstacles. Firstly, post-processing assembly extends the time and cost of the process chain to ensure accurate alignment and movement, especially if the microfabrication process itself is relatively slow. Secondly, in case of in-situ assembly using silicon etching or similar techniques, the process is not mature enough for mass-fabrication.

This paper presents a technique using metal powders to produce moving components with dimensionally controlled micro-scale interfaces by $\mu \mathrm{PIM}$ as a high-volume microfabrication process. A review of the uPIM and its applications for micro-scale components is available in the literature (Attia and Alcock, 2011a). The following sections detail the proposed methodology through a demonstrator, and the discussion will assess the capability of the proposed technique to overcome the five challenges highlighted above. 


\section{Experimental}

Here we report on a strategy by which articulated architectures with micro-scale 3-D cavities can

be fabricated using a lost-core approach. The authors have previously demonstrated the possibility of producing dimensionally controlled, enclosed micro-cavities by sequential powder over-moulding of metals (Attia and Alcock, 2012 ) and ceramics (Attia and Alcock, 2011b).

The hypothesis explored here was that a further development of such a methodology could be used to create "open" cavities/spaces between two or more components, such that the components could move relative to each other. Figure 1 presents a schematic illustration of the technique.

98

100

101

102

103

104

105 extracted during the process. The resulting space allows for a relative motion between the two

Briefly, one component is fabricated out of a metallic feedstock by $\mu$ PIM. A micro-scale polymeric sacrificial layer is then overmoulded in the position relative to the first component at which a cavity is eventually required. The second component, made of powder feedstock, is overmoulded on top of the polymeric layer, ensuring, in the design and fabrication steps, that it has no contact points with the first component.

The resulting rigid structure is then catalytically debound, where nitric acid vapour is used to hydrolyse the POM of both the sacrificial layer and the components' binder into formaldehyde, which is components, which are subsequently sintered for full densification. 
118 polymer, in this case polyoxymethylene (POM). The sacrificial layer is made of the same polymer so that

119 both the polymeric content of the powder feedstock and the core could be simultaneously eliminated

120 during catalytic debinding.

121 Stainless steel 316L was the material selected for this experiment for two main reasons. Firstly,

122 stainless steel 316L is commercially available as a readily mixed feedstock consisting of powder particles

123 with relatively small mean sizes $(4-5 \mu \mathrm{m})$, which makes it suitable for micro-moulding applications.

124 Using a commercial grade of feedstock makes it possible to assess the viability and consistency of the

125 proposed process independent of factors related to mixing special medical grade powders.

126 The second reason for using $316 \mathrm{~L}$ is that it is one of the most widely used materials for

127 replicating conventional and micro-scale features by metal injection moulding (MIM). There is a

128 considerable amount of previous work that looked into investigating different aspects of the powder

129 injection moulding of $316 \mathrm{~L}$.

130 For example, with regard to mixing and characterising $316 \mathrm{~L}$ feedstock, Liu et al. (2005) used

$131316 \mathrm{~L}$ to assess the effects of powder loading and mixing conditions on feedstock homogeneity and shape

132 retention of micro-moulded features. Abolhasani and Muhamad (2010) developed a new 316L feedstock

133 for MIM based on starch as a binding material. Samanta et al. (2011) characterised the thermo-physical

134 properties of an in-house mixture of a 316L feedstock for MIM. Kong et al. (2012) demonstrated a

135 procedure to determine the optimal powder loadings for 316L stainless steel feedstock for micro-powder

136 injection moulding.

137 With regard to process development, Loh et al. (2003) used 316L feedstock to replicate

138 microstructure arrays with aspects ratios up to 2 using silicon inserts. Their work focused on the effect of

139 process conditions on replication quality of micro-scale features.

140 Debinding 316L has also been investigated in a number of experiments. For example, Omar et al.

141 (2003) demonstrated a two-stage rapid debinding technique combining solvent and thermal debinding of

142 316L feedstock. Li et al. (2003) compared the binder removal rate in vacuum and hydrogen environments

143 during thermal debinding of 316L. The effect of thermal debinding of 316L feedstock on surface

144 roughness of moulded components was also studies by Liu et al. (2007). 
146 sinter-bonding of two 316L components produced by micro-metal injection moulding. Nishiyabu et al.

147 (2007) demonstrated a lost-core technique to produce microstructured 316L components by micro-

148 injection moulding. In addition, Imgrund et al. (2008) co-injection moulded 316L and 17-4PH to produce

149 magnetic-nonmagnetic bimetals by micro-MIM. 316L powder was also used by Manonukul et al. (2010)

150 to demonstrate a technique to produce metal foam by metal injection moulding using a powder space

151 holder.

152 With regard to properties of sintered 316L components, Castro et al. (2003) studied the

153 mechanical properties and pitting corrosion behaviour of 316L. Tay et al. (2005) investigated the effect of

154 sintering conditions on the surface roughness of microstructured components produced by injection

155 moulding of 316L. Huang and Hsu (2009) compared the effect of three backbone polymers on the

156 mechanical properties of 316L specimens produced by MIM, showing that HDPE performs best in terms

157 of both the flow stability and the MIM compact quality. Rafi Raza et al. (2012) studied the effects of

158 cooling rate on mechanical properties and corrosion resistance of vacuum sintered powder injection

159 moulded 316L stainless steel. They showed that higher cooling rates improved mechanical properties and

160 corrosion resistance compared to lower cooling rates.

161 Catalytic debinding was particularly selected for the process route presented in this paper,

162 because it is a direct solid-gas transition process that takes place below the $\mathrm{T}_{\mathrm{g}}$ of the polymer. The process,

163 therefore, results in higher dimensional accuracy, tighter tolerances and better surface finish relative to

164 other debinding techniques (German, 1998). Such characteristics make catalytic debinding an attractive

165 process for applications requiring dimensional accuracy and tight tolerances. A recent market study has

166 showed that $21 \%$ of the MIM industry currently relies on catalytic debinding (German and Atre, 2013)

167 Catalytic debinding of 316L has been investigated in several experiments. Examples include the

168 work reported by Fu et al. (2004), where the use of uMIM to produce 316L microstructural arrays of

169 high-aspect ratios was investigated in a process that involved catalytic debinding. The same group also

170 studied the effect of moulding process parameters on the filling quality of the array microstructures (Fu et

171 al., 2005a) and used catalytic debinding to produce microstructural arrays made of $316 \mathrm{~L}$ with good shape

172 retention (Fu et al., 2005b). 


\subsubsection{Structure design and operation}

The application presented in the paper is a finger bone replacements, which has component sizes in the order of few millimetres and tolerances in the order of hundreds of micrometres. Similar prosthesis are usually fabricated as separate components and assembled by post processing as previously discussed in the introduction. selected as a demonstrator for the proposed process for a number of reasons:

182 i. The structure consists of moving components with micro-scale tolerances in the order of hundreds of microns.

184 ii. The geometries of the subcomponents are three-dimensional in nature, with free-form surfaces within the joint itself, which makes them unsuitable for conventional $2 \frac{1}{2}-\mathrm{D}$ manufacturing processes.

iii. The structure requires assembling the two-subcomponents, which is done as a post-processing step in state-of-the-art designs, and which this work attempts to do it in-situ (more details about the design of the assembly mechanism in the description of figure 2 below).

iv. Such a component poses special material requirements in terms of mechanical properties and biocompatibility, which could be fulfilled with powder technology. as "part 1" and "part 2", respectively, throughout the text.

Figure 2 shows a CAD illustration of the structure with the main dimensions. The structure

196 consists of two sub-components joined in a cylinder-and-socket format with a one-degree-of-freedom

197 (DOF) mobility. 

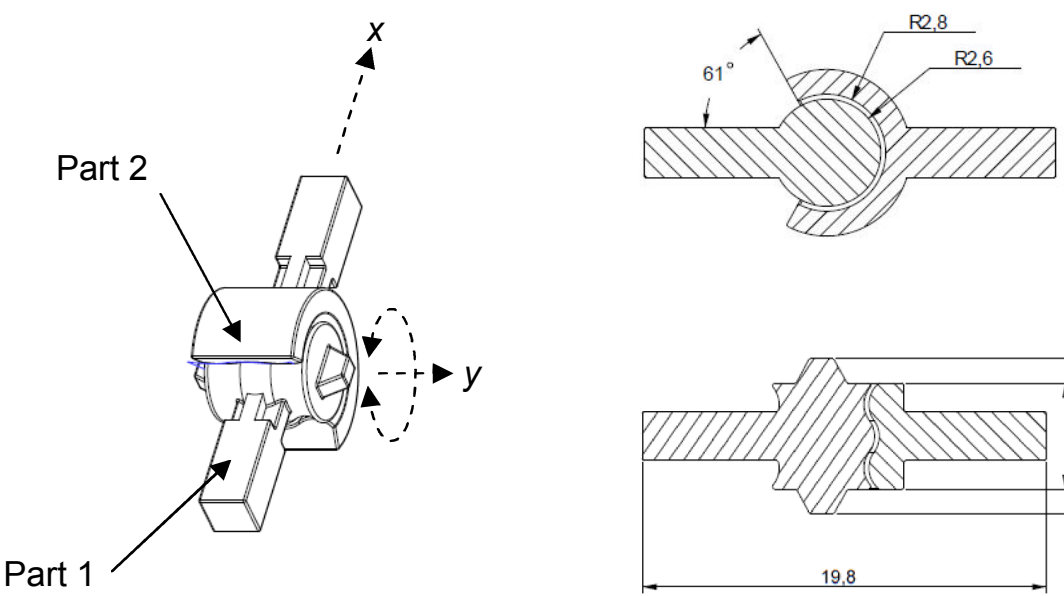

212 Fig. 2. A CAD illustration of the moving joint (all dimensions are in millimetres).

The in-situ assembly mechanism is achieved through the free-form design of the mating surfaces

215 of the subcomponents that are designed such that they are inseparable throughout the manufacturing process. This design philosophy constrains the relative motions of parts 1 and 2 in all directions, except

217 for the required 120-degree rotational movement around the $y$-axis. Part 1 is designed as a cylinder with a symmetrical curved surface. A similar curvature is introduced into the inside geometry of the socket of part 2, leaving a space of $200 \mu \mathrm{m}$ between the mating surfaces of Parts 1 and 2, such that the two components are constrained in all translational and rotational directions except for rotation around the $y$ direction (figure 2).

Part 2 is designed such that the $\mathrm{C}$-shape partially surrounds the cylinder of part 1 making them inseparable in the $x$-or $z$-directions. The $\mathrm{C}$-shape of part 2 is designed to allow the required a rotation angle of $120^{\circ}$ around the $y$-axis.

Both the cylinder and socket are attached to two "arms" that would be inserted into the bones during an operation to insert the prosthesis. In a finalized design, the two arms should have a particular

227 design and structure to fulfil this purpose. In this particular case, they were designed as plain squaresectioned geometries for simplicity. The arms are connected to the cylinder and socket by four ribs each. 2.2.2 Fabrication methodology and procedure.

The mould used in this experiment was designed such that a replaceable steel insert carries the cavity that is filled with the feedstock during each moulding stage. This enables a quick replacement of 

replaceable part of the mould that carries the required cavity.

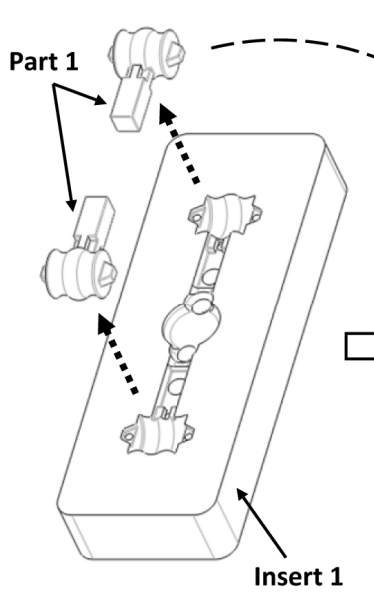

[a]

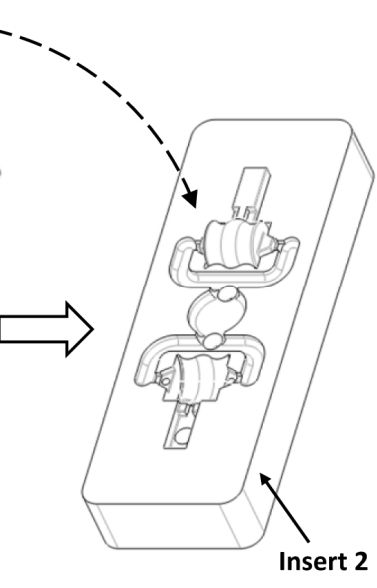

[b]

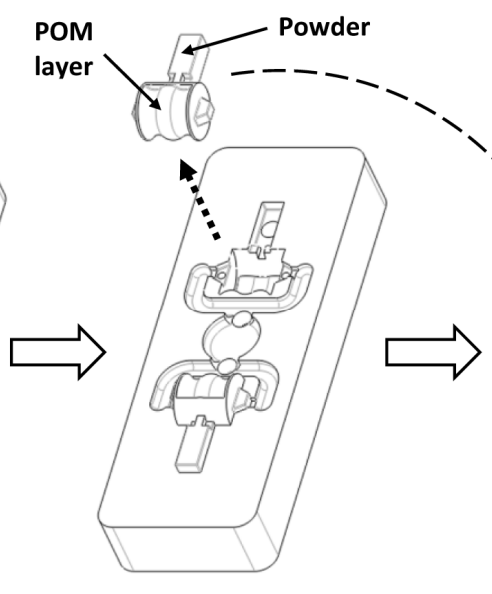

[c]

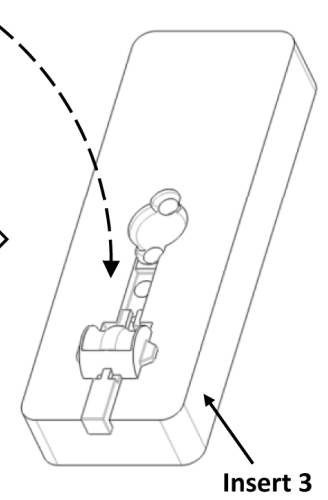

[d]

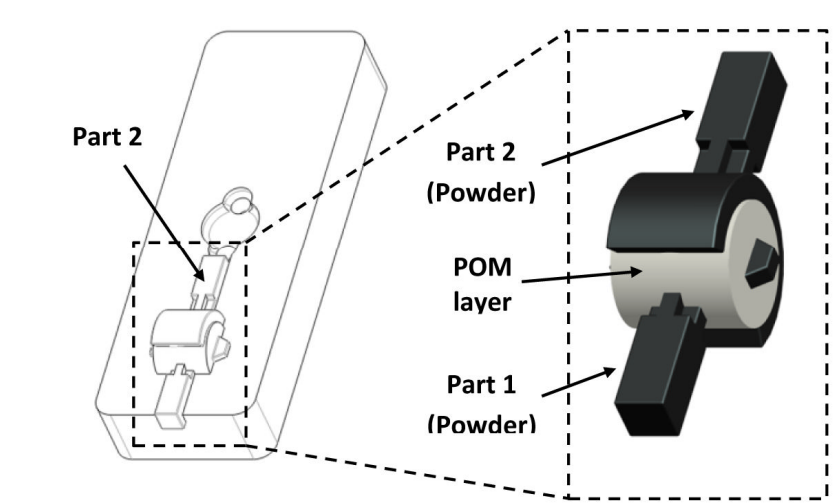

[e]

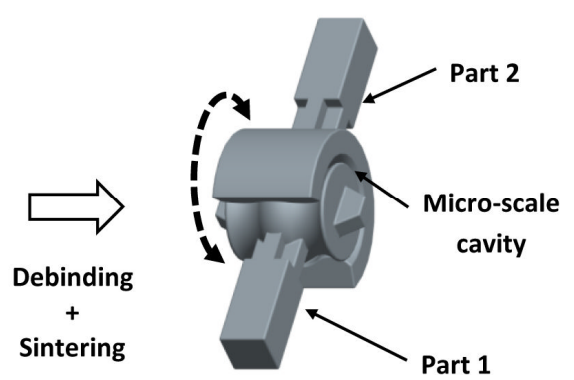

[f]

Fig. 3. A schematic diagram of the moulding process of a hybrid structure: (a) two pieces of Part 1 are moulded of 316L and ejected from insert 1. (b) Part 1 pieces are placed in the cavities of insert 2. (c) Part 1 pieces are overmoulded by 200-micron layers of POM and ejected. (d) One overmoulded structure is placed in the cavity of insert 3 ready for the second overmoulding step. (e) In the second overmoulding stage, Part 2 is moulded of 316L, resulting in a hybrid structure of Part1, POM layer and Part 2. (f) After debinding and sintering, Part 2 is movable relative to Part 1.

- Step 2: Part 1 is positioned inside another insert that is machined with extra cavity space for the polymer layer. 
- Step 3: The sacrificial polymeric layer is micro-overmoulded around part 1 in the defined cavity space.

- Step 4: The resulting compound structure is positioned in a third insert that holds the cavity of part 2.

- $\quad$ Step 5: Part 2 is overmoulded by $\mu$ PIM using a powder feedstock.

- Step 6: The resulting compound structure is catalytically debound, resulting in the removal of the polymeric content, including the sacrificial layer.

- Step 7: The resulting structure is sintered for full densification.

The procedure shown in figure 3 illustrates that three micro-moulds are required to produce the 'green' compound structure. These moulds were fabricated as replaceable inserts in a single mould body. The six halves of the inserts were fabricated by micromilling.

Such complex structures required special micro-cutting tools and special machining sequences,

277 particularly during the finishing stage, to control the final micro-space between the moving components.

278 Sintering shrinkage for the selected powder material is typically between $14 \%$ and $16 \%$, so oversized

279 mould cavities were designed and machined taking the final size of the structure into consideration. machine. A set of cutting micro-tools was used to cut and finish the inserts, where each cavity is machined with three roughing stages and one finishing stage. Table 1 summarizes the machining procedure for the three inserts.

Table 1. Micromilling procedure for the three inserts.

\begin{tabular}{|c|c|c|c|c|c|c|c|c|c|}
\hline & \multicolumn{3}{|c|}{ Mould 1} & \multicolumn{3}{|c|}{ Mould 2} & \multicolumn{3}{|c|}{ Mould 3} \\
\hline & $\begin{array}{l}\text { Tool } \\
\text { dia. } \\
(\mathrm{mm})\end{array}$ & $\begin{array}{l}\text { Rot. } \\
\text { Speed } \\
(\mathrm{rpm})\end{array}$ & $\begin{array}{l}\text { Feed } \\
\text { rate } \\
(\mathrm{mm} / \mathrm{mi} \\
\mathrm{n})\end{array}$ & $\begin{array}{l}\text { Tool } \\
\text { dia. } \\
(\mathrm{mm})\end{array}$ & $\begin{array}{l}\text { Rot. } \\
\text { Speed } \\
(\mathrm{rpm})\end{array}$ & $\begin{array}{l}\text { Feed } \\
\text { rate } \\
(\mathrm{mm} / \mathrm{mi} \\
\mathrm{n})\end{array}$ & $\begin{array}{l}\text { Tool } \\
\text { dia. } \\
(\mathrm{mm})\end{array}$ & $\begin{array}{l}\text { Rot. } \\
\text { Speed } \\
(\mathrm{rpm})\end{array}$ & $\begin{array}{l}\text { Feed } \\
\text { rate } \\
(\mathrm{mm} / \mathrm{mi} \\
\mathrm{n})\end{array}$ \\
\hline Roughing & 1 & 17600 & 530 & 1 & 17600 & 530 & 1 & 17600 & 530 \\
\hline $\begin{array}{l}\text { Re- } \\
\text { roughing } 1\end{array}$ & 0.5 & 38000 & 480 & 0.5 & 38000 & 338 & 0.5 & 38000 & 369 \\
\hline $\begin{array}{l}\text { Re- } \\
\text { roughing } 2\end{array}$ & 0.5 & 38000 & 404 & 0.5 & 38000 & 512 & 0.5 & 38000 & 500 \\
\hline Finishing & 0.4 & 41000 & 420 & 0.4 & 41000 & 420 & 0.2 & 41000 & 26 \\
\hline
\end{tabular}


Powder micro-moulding was used to produce the green hybrid structure following the procedure above. The moulding conditions of both the powder feedstock and the polymer layer are shown in table 2 .

Table 2. Moulding conditions for POM and powder/POM.

\begin{tabular}{llllll}
\hline Material & $\begin{array}{l}\text { Melt } \\
\text { temperature }\left[{ }^{\circ} \mathrm{C}\right]\end{array}$ & $\begin{array}{l}\text { Mould } \\
\text { temperature }\left[{ }^{\circ} \mathrm{C}\right]\end{array}$ & $\begin{array}{l}\text { Holding } \\
\text { pressure }[\text { bar }]\end{array}$ & $\begin{array}{l}\text { Injection } \\
\text { velocity } \\
{[\mathrm{mm} / \mathrm{s}]}\end{array}$ & $\begin{array}{l}\text { Cooling time } \\
{[\mathrm{s}]}\end{array}$ \\
\hline POM & 190 & 100 & 300 & 250 & 10 \\
Powder / POM & 190 & 140 & 300 & 250 & 10 \\
\hline
\end{tabular}
with melt flow index of 25 to ensure better filling of micro-cavities; the powder feedstock was composed of a mixture of $316 \mathrm{~L}$ stainless steel particles with average particle size $\left(d_{50}\right)$ of $4 \mu \mathrm{m}$ and POM (BASF

\section{Catamold $^{\circledR}$ 316LS).}

\subsubsection{Catalytic debinding and sintering}

300 During debinding, the compound green structures were placed on a loose-powder bed of alumina

301 for two reasons: Firstly, the powder was used to support the two arms of parts 1 and 2. This is because

302 when the two parts become detached from each other after the removal of the polymer, the torque

303 produced by the weight of the two arms might cause the corresponding parts to tilt against each other and

304 touch at some point, which upon sintering could form a permanent joint. Secondly, the powder bed offers

305 a "flexible" substrate that would not restrict the uniform shrinkage of the two parts due to, for example,

306 friction. The loose powder would allow a simultaneous uniform volumetric shrinkage to take place in the

307 two parts, including the gap in-between, without geometrical deformation.

308 Catalytic debinding took place following the BASF technique (Bloemacher and Weinand, 1997)

309 at a dwell temperature of $110^{\circ} \mathrm{C}$ in high-concentration nitric acid $(>98 \%)$ at an acid feed of approximately

$31030 \mathrm{ml} / \mathrm{h}$. Debinding takes place following the so-called "shrinking core mechanism", by which POM is

311 eliminated layer-by-layer from the outside into the core. Nitrogen was used as a purging gas at a flow rate

312 of approximately $500 \mathrm{l} / \mathrm{h}$. The debinding cycle takes approximately 5 to 6 hours.

313 After debinding, the structure was composed of parts 1 and 2 in powder form between which

314 there was a hollow space. At this stage, the two components were technically separate, although they 
315 were fixed in place using the powder bed. The resulting 'brown' components were taken directly to the

316 sintering oven while on the powder platform.

317 Sintering was conducted following the schedule shown in table 3, with hydrogen as the gaseous

318 environment. The alumina powder bed facilitated the sintering process by holding the components in

319 place and at the same time allowing them to shrink without bringing them to contact during sintering.

320

321

322

323

324

325

326

327

328

329

Table 3. Typical sintering schedule for Catamold 316L debound structures.

\begin{tabular}{ll}
\hline Stage & Schedule \\
\hline 1 & From room temperature to $600^{\circ} \mathrm{C}$ at the rate of $3^{\circ} \mathrm{C} / \mathrm{min}$. \\
2 & Hold at $600^{\circ} \mathrm{C}$ for $1 \mathrm{~h}$. \\
3 & From $600^{\circ} \mathrm{C}$ to $1250^{\circ} \mathrm{C}$ at the rate of $3^{\circ} \mathrm{C} / \mathrm{min}$. \\
4 & Hold at $1250^{\circ} \mathrm{C}$ for $1 \mathrm{~h}$. \\
5 & From $1250^{\circ} \mathrm{C}$ to $600^{\circ} \mathrm{C}$ at the rate of $5^{\circ} \mathrm{C} / \mathrm{min}$. \\
6 & Furnace cooling. \\
\hline
\end{tabular}

The density of the sintered components has been measured using the Archimedes principle, and hardness values have been measured by nanoindentation. Both values have been compared to the theoretical values supplied by the material manufacturer.

\section{Results}

Figure 4 shows the results of the micro-machining and micro-overmoulding procedure described earlier in section 2.2.2.

\section{(a)}

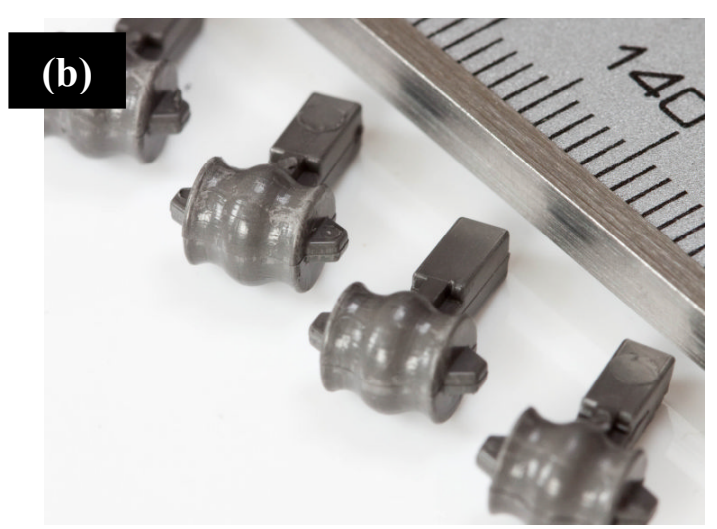



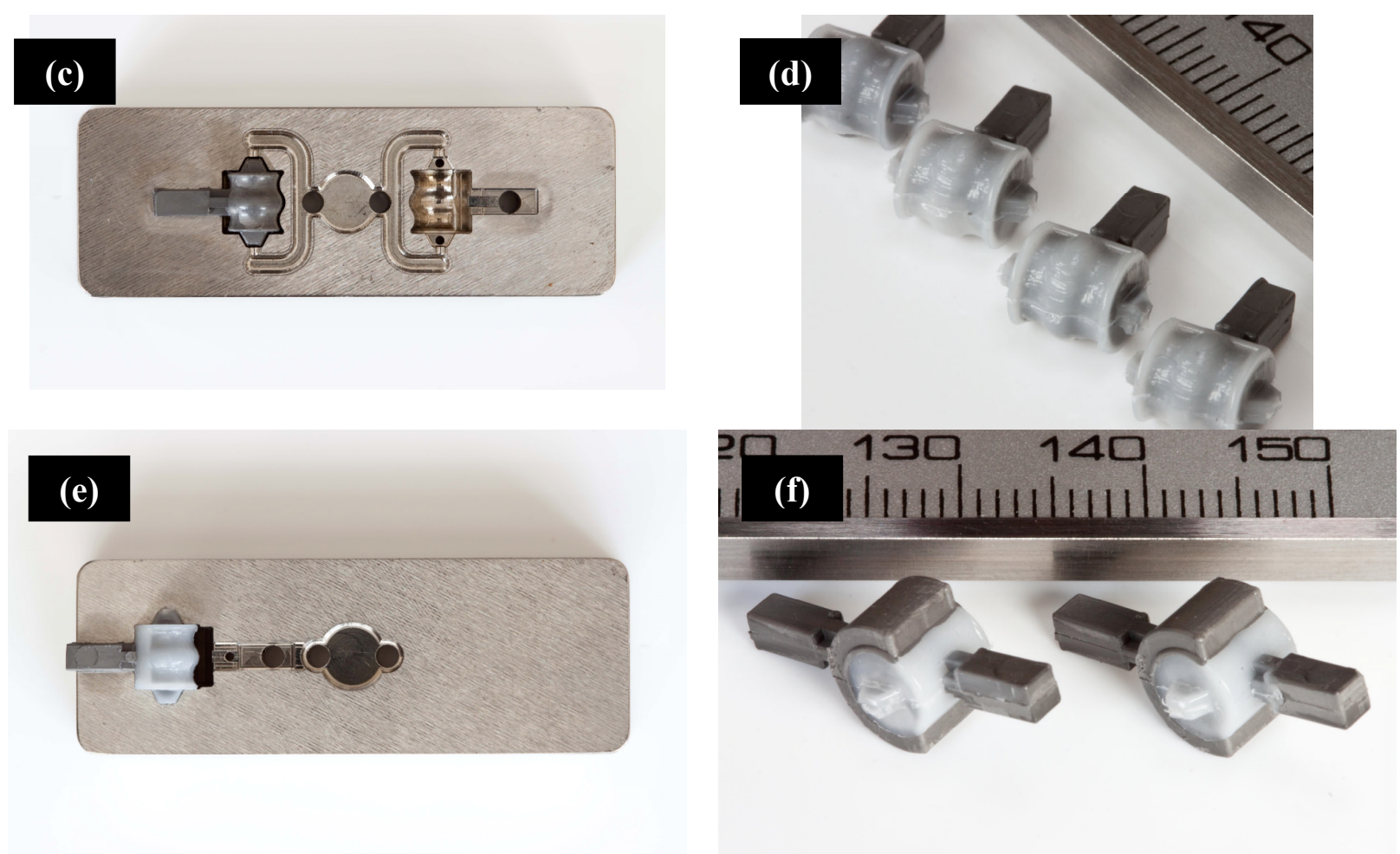

Fig. 4. (a) a twin-cavity insert for part 1 (b) part 1 samples replicated from 316LS feedstock (c) a twincavity insert for POM layer with part 1 sample placed in one cavity for illustration (d) part 1 samples micro-overmoulded with POM layers (e) an insert for component 2 with the overmoulded part 1 for illustration (f) samples of the complete hybrid green structure of parts 1 and 2 with the POM layer.

\section{(e)}

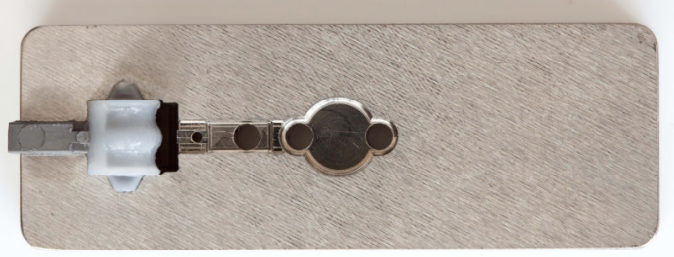

Figures $4 \mathrm{a}$ and $4 \mathrm{~b}$ show the mould of part 1 and the replicated green component, respectively.

337 The micro-moulding of the sacrificial POM layer is shown in figures $4 \mathrm{c}$ and $4 \mathrm{~d}$, where the former shows

338 the mould in which part 1 was positioned, and the latter shows part 1 covered with the sacrificial POM layer where the moving space is eventually required. Figure $4 \mathrm{c}$ shows how the mould was designed with two registration cavities to secure the positioning of part 1 inside the mould whilst the POM layer is being overmoulded. The overmoulding of part 2 is shown in figures $4 \mathrm{e}$ and $4 \mathrm{f}$, where the former shows the third, and final, mould cavity, and the latter shows the full compound hybrid structure.

Figure 5 shows a cross section in the hybrid green structure. The figure shows a symmetric layer of POM between parts 1 and 2 with variable thickness. Measurements indicate an average thickness of $246 \mu \mathrm{m}$ at narrowest distance in the middle. The largest distances at the sides have average thicknesses of $367 \mu \mathrm{m}$. 


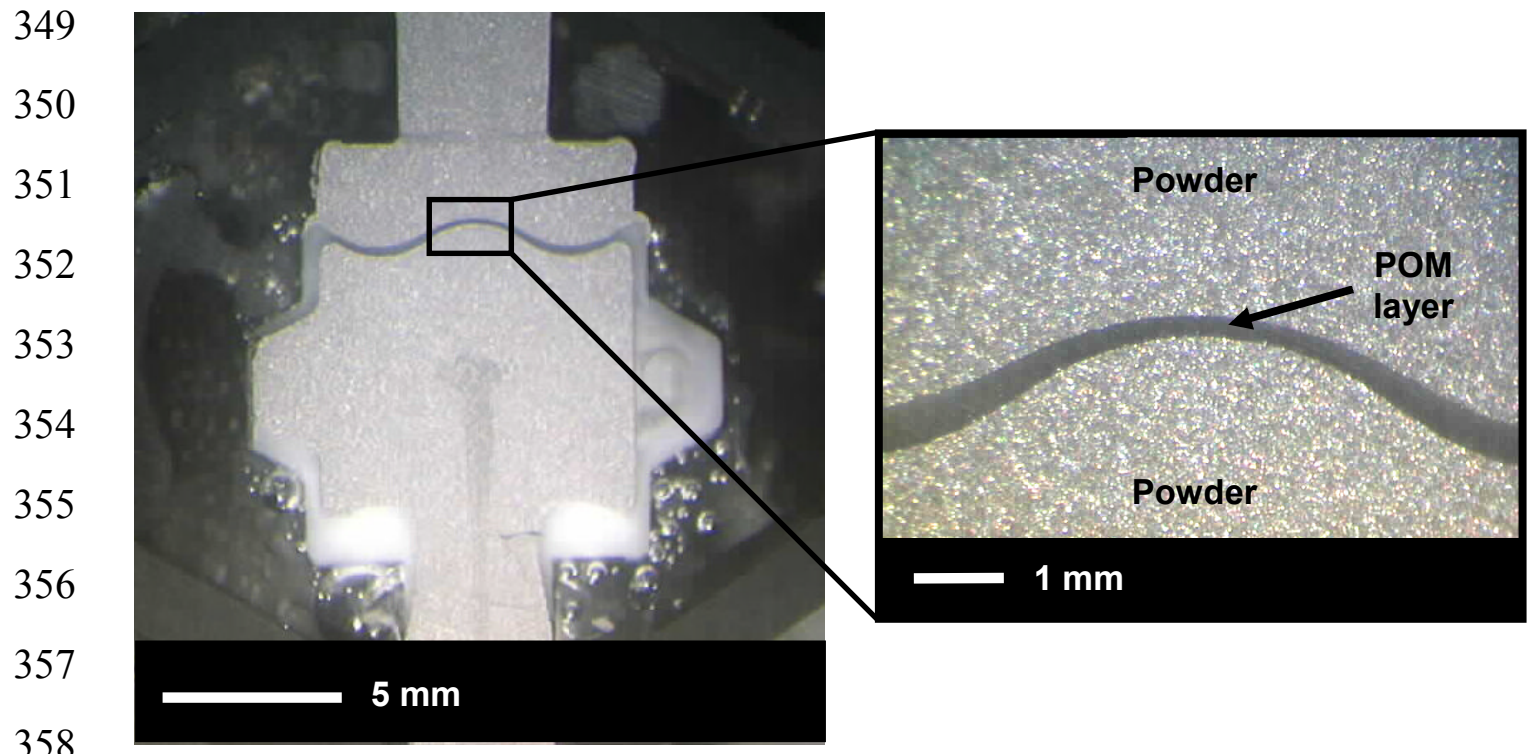

359 Fig. 5. A cross section in a green structure with an enlarged view of the micro-sacrificial layer.

360

Figure 6 shows a batch of "brown" structures after catalytic debinding positioned on the powder

362 bed. The figure shows each structure consisting of two distinct components with a cavity in between with

363 no visible traces of polymeric material.

364

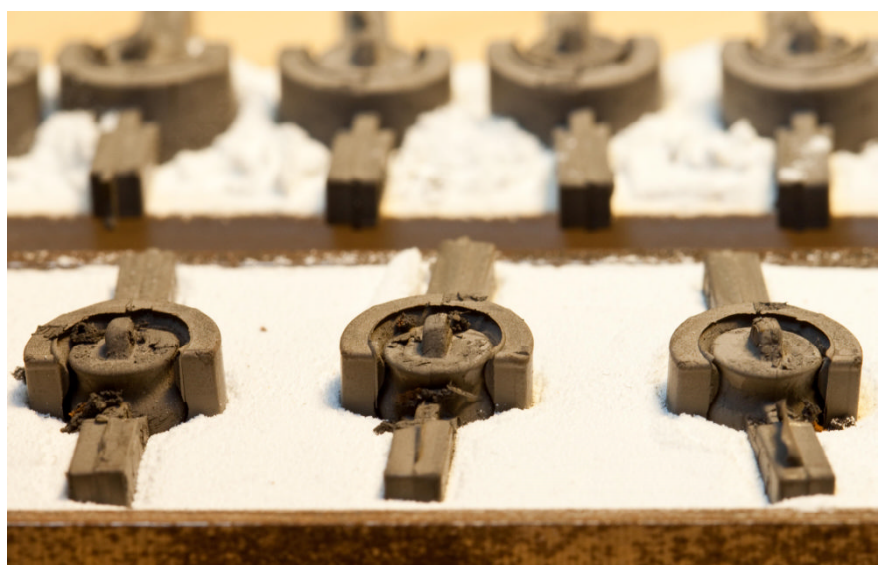
sub-components. 


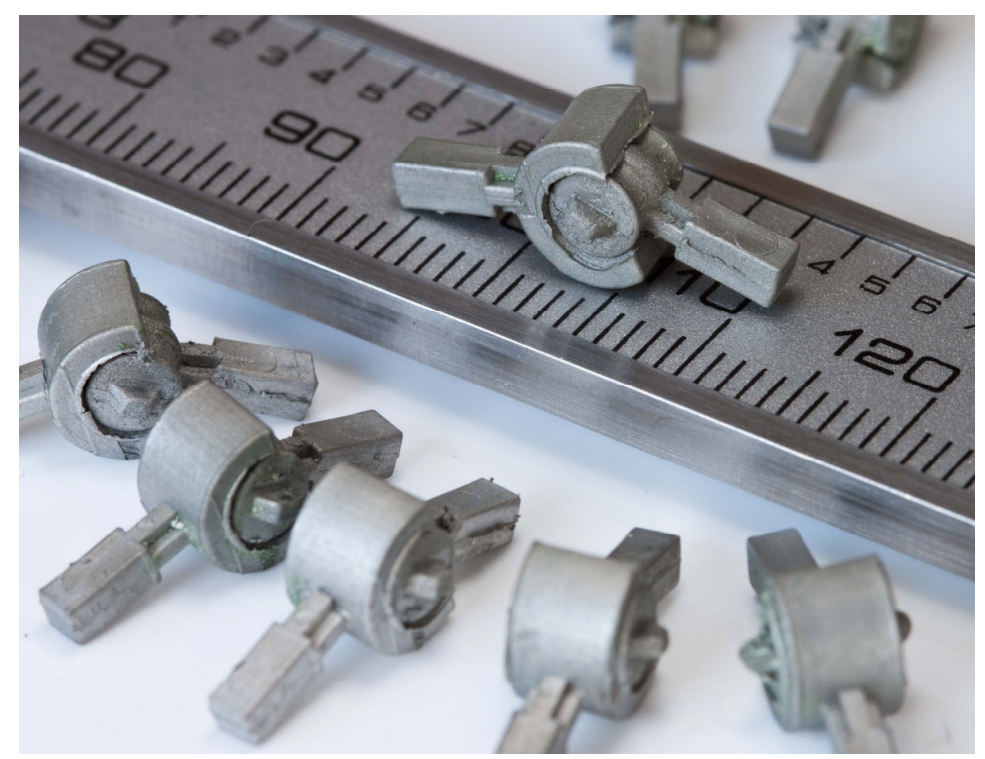

371 Fig. 7. Sintered structures with movable joints. features. The images show the micro-cavity between the two subcomponents.
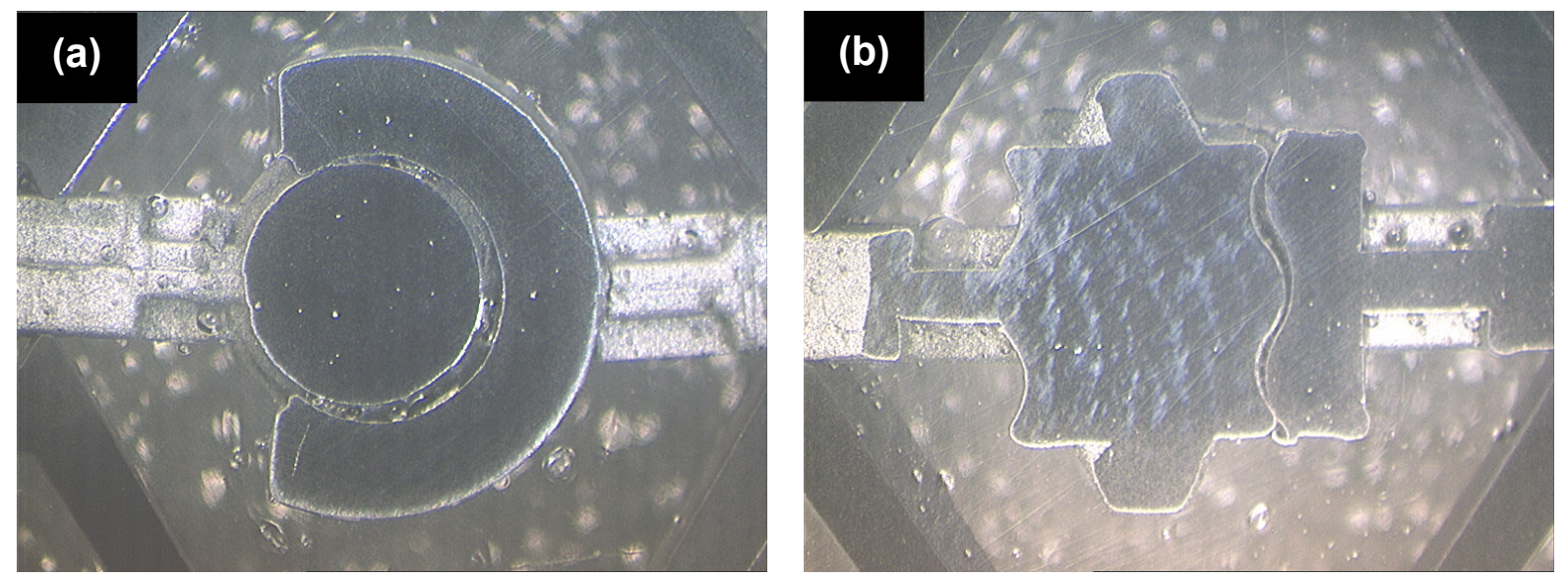

Fig. 8. Cross sections in the sintered structure (a) normal to the rotation axis and (b) parallel to the registration features. average distance of approximately $218 \mu \mathrm{m}$ was measured. The results illustrated in figures 7 and 8 show that the presented manufacturing technique is viable for producing micro-scale movable interfaces. The micro-overmoulding sequence in figure 4 shows that it is feasible to micro-mould dimensionally 

how the proposed process chain has addresses the five challenges highlighted in section 1 . is also presented as a percentage of the theoretical density specified by the material datasheet $\left(7.9 \mathrm{~g} / \mathrm{cm}^{3}\right)$.

389

390

391

392

393

394

395

396

397

398

399

400

401

402

403

Table 4. Density measurements of six sintered samples

\begin{tabular}{ccc}
\hline No. & Density $\left[\mathrm{g} / \mathrm{cm}^{3}\right]$ & \% theoretical \\
\hline 1 & 6.577 & 83 \\
2 & 6.533 & 83 \\
3 & 6.670 & 84 \\
4 & 6.548 & 83 \\
5 & 6.716 & 85 \\
6 & 6.651 & 84 \\
\hline Av. & 6.616 & 83.7 \\
\hline
\end{tabular}

Table 5 presents the results of Vickers hardness values obtained by nanoindentation measurements of five samples. The measurements were taken in two locations with 200-gram load: (a) on the circular section of part 1 and (b) on the arm section of part 2.

Table 5. Micro-hardness measurements of five samples in two locations.

\begin{tabular}{ccc}
\hline No. & Part 1 hardness [HV] & Part 2 hardness [HV] \\
\hline 1 & 121 & 132 \\
2 & 123 & 122 \\
3 & 124 & 99 \\
4 & 119 & 132 \\
5 & 124 & 135 \\
\hline Av. & 122.2 & 124 \\
\hline
\end{tabular}

\section{Discussion}

In light of the results of section 3, this section evaluates how the proposed methodology addressed the processing challenges of meso- and micro-scale joints highlighted in the introduction. With regard to the geometrical challenge, the results of figure 4 show that the process is viable in two aspects. Firstly, the micro-overmoulding procedure was performed for truly three-dimensional geometries with free-form surfaces, and the images of the moulded components in figure 4 (b, d and f) show good replication fidelity. Secondly, it was suspected that using the same polymer (POM) for both the powder matrix and the core might increase the likeliness of deformation at the interface due to the similar thermal properties. However, this was not observed during processing, and the cross section in 
407 figure 5 shows a hybrid green component with good shape retention and clear boundaries between the

408 powder shell and the polymer micro-layer.

409 With regard to the material variety challenge, the presented process is applicable to any powder-

410 base mouldable feedstock. Commercially available feedstock covers a wide range of metals and ceramics

411 with different mechanical, thermal and biomedical properties. In addition, powder feedstock with

412 relatively small average particle sizes (in the order of few micrometres for metals and a few hundred

413 nanometres for ceramics) is available, which enables the replication of meso- and micro-scale

414 components. The presented process, therefore, offers a true shift from conventional materials associated

415 with microfabrication such as silicon and SU8.

416 With regard to the assembly challenge, figures 5 and 6 show that the two parts are readily

417 assembled and movable relative to each other. This was achieved in-situ by combining a design solution

418 with a processing solution. The former was concerned with designing the internal geometries of both

419 parts such that they are inseparable once a cavity is created between them. The latter solution was

420 concerned with planning the processing steps such that alignment is readily achieved during the

421 overmoulding stages by using registration marks and positioning constraints in the mould structure. This

422 manufacturing strategy enables in-situ assembly, alignment and motion already after the debinding stage,

423 The sintering stage was just to treat the components into the final density.

424 With regards to powder-based fabrication challenges, figure 6 of the debound components shows

425 that the manufacturing principle is viable for producing sacrificial micro-cavities for powder-based

426 moving joints. Unlike previous work reported in the literature that relied on controlling shrinkage rates to

427 produce a movable interface, this approach overcomes this challenge by creating the interface through a

428 micro-moulded sacrificial layer that precisely defines the final clearance between the moving components.

429 The images show that the POM micro-layer was totally consumed whilst the overall component

430 retains its geometry. Other than a few defects inherited from the moulding process, such as the broken-

431 gate remains or ejection-pin marks, the debinding process did not distort the geometrical integrity of the

432 structure.

433 The cross sections of the sintered component illustrated in figure 8 show the cavity maintained in

434 the structure. No visible signs of deterioration have been detected, and shape retention appears of high

435 quality. Again no signs of particular problems related to cavity encapsulation were observed. The 
$43711 \%$ from the $246-\mu \mathrm{m}$ POM layer. This shrinkage is slightly lower than the $14 \%$ specified by the powder

438 feedstock datasheet, which implies the need for better process control during sintering.

439 Density measurements reported in Table 4 show that the component density is about $84 \%$ of the

440 theoretical density specified by the material manufacturer. This could be explained by the fact that

441 sintering took place at $1250^{\circ} \mathrm{C}$ (maximum allowed by the equipment available), which is 100 degrees

442 lower than the recommended $1360^{\circ} \mathrm{C}$ sintering temperature recommended by the material supplier. The

443 lower temperature was not sufficient to reach full densification. This also explains the lower value of

444 shrinkage discussed earlier.

445 Hardness values reported in Table 5 shows that average values for Part 1 (122 HV) and Part 2

$446(124 \mathrm{HV})$ are close to the theoretical value specified by the material datasheet $(120 \mathrm{HV})$. The variation in

447 the hardness measurements reported in Table 5 could be due to error in measurements due to the small

448 sizes of the samples.

449 With regard to mass manufacturability, micro-moulding of polymers is already being

450 implemented on an industrial scale, and micro-moulding of metals has the same potential. The moulding

451 processes themselves are relatively short (tens of seconds), and the longest time was used to position the

452 components manually into the inserts at each overmoulding stage. Automating the insert loading process

453 would overcome this obstacle on a mass-manufacturing scale.

$454 \quad$ Figures 7 and 8 indicate the feasibility of the presented process chain in producing metallic

455 movable joints with micro-scale interface by $\mu$ PIM after addressing the main five challenges highlighted

456 in the introduction. It should be noted, however, that the fabrication strategy has a number of limitations

457 that need to be addressed. One limitation is that each stage of the process is effectively a micro-moulding

458 process, which requires the geometry design to be demouldable from a two-half mould. This limits the

459 producible geometries relative to, for example, SLS. In addition, all dimensions of the powder

460 components are limited by the particle size, as it is recommended that the minimum feature size should be

461 at least 10-20 times the particle size, as recommended by German (2009) and Piotter et al. (2005).

462 It should also be noted that the dimensional accuracy of the replicated components can be as

463 good as the corresponding mould dimensions themselves. Although the designed distance between the

464 moving components was $235 \mu \mathrm{m}$, the actual moulded POM layer was $246 \mu \mathrm{m}$ at its narrowest point due 
to machining variations. This resulted in a post-sintered cavity distance of $218 \mu \mathrm{m}$ with an extra $9 \%$ increase in cavity size. process control. Research will also focus on implementing the process for smaller structure size and a variety of powder materials.

470

\section{Conclusion}

This paper presents a processing strategy for creating micro-scale cavities between moving components. The proposed process route combines the capabilities of powder micro-moulding, microovermoulding, catalytic debinding and sintering. An articulated structure with a single degree of freedom was used as a demonstrator for the technology. The produced components showed that the process routes are feasible and no serious challenges were encountered, except for the need to investigate other mouldfabrication methods and optimise process conditions for dimensional control. Density measurements showed that the components were approximately $84 \%$ of the theoretical density, which is due to sintering taking place below the recommended temperature. Hardness measurements showed average values close to the theoretical values. Further experimentation is required to assess the feasibility of the process for smaller, micro-scale dimensions and for different powder-based materials.

\section{Acknowledgements}

484 The authors would like to thank the EPSRC and the Cranfield IMRC for their support of this work.

\section{References}

487 Abolhasani, H., Muhamad, N., 2010. A new starch-based binder for metal injection molding. J. Mater. Process. Tech., 210, 961-968.

489 Attia, U. M., Alcock, J. R., 2011a. A review of micro-powder injection moulding as a microfabrication technique. J. Micromech. Microeng., 21, art. no. 043001.

491 Attia, U. M., Alcock, J. R., 2011b. Fabrication of ceramic micro-scale hollow components by micropowder injection moulding. J. Eur. Ceram. Soc., 32, 1199-1204 
Attia, U. M., Alcock, J. R., 2012. Fabrication of hollow, 3D, micro-scale metallic structures by micropowder injection moulding. J. Mater. Process. Tech., 212, 2148-2153.

Bloemacher, M., Weinand, D., 1997. Catamold - a new direction for powder injection molding. J. Mater. Process. Tech., 63, 918-922.

Castro, L., Merino, S., Levenfeld, B., Várez, A., Torralba, J.M., 2003. Mechanical properties and pitting corrosion behaviour of 316L stainless steel parts obtained by a modified metal injection moulding process. J. Mater. Process. Tech., 143-144, 397-402.

Fan, L., Tai, Y., Muller, R. S., 1988. Integrated movable micromechanical structures for sensors and actuators. IEEE T. Electron. Dev., 35, 724-730.

Field, J., 2008. Two to five year follow-up of the LPM ceramic coated proximal interphalangeal joint arthroplasty. J. Hand Surg.-Eur. Vol., 33, 38-44.

Fu, G., Loh, N. H., Tor, S. B., Murakoshi, Y., Maeda, R, 2004. Replication of metal microstructures by

Fu, G., Loh, N. H., Tor, S. B., Murakoshi, Y., Maeda, R., 2005a. Effects of injection molding parameters 20, 977-985.

Fu, G., Loh, N. H., Tor, S. B., Tay, B. Y., Murakoshi, Y., Maeda, R., 2005b. Injection molding, debinding and sintering of 316L stainless steel microstructures. Appl. Phys. A-Mater., 81,495-500.

511 German, R. M., 1998. A rationalization of the powder injection molding process for stainless steels based on component feature. International Conference and Exhibition on Powder Metallurgy and Particulate Materials, pp 5.71-5.83.

514 German, R. M., 2009. Medical and dental applications for microminiature powder injection moulding

515 (microPIM) - a roadmap for growth. PIM International, 3, 21-29.

516 German, R. M. and Atre, S. V., 2013. Pro Forma Report of Trends and Forecasts for PIM. Online source at: http://pim2013marketstudy.scipivision.com. Accessed 2013.

518 Hassanin, H., Jiang, K., 2010. Optimized process for the fabrication of zirconia micro parts.

$519 \quad$ Microelectron. Eng., 87, 1617-1619. 
Hergert, R., Ku, I. S. Y., Reddyhoff, T., Holmes, A. S., 2010. Micro rotary ball bearing with integrated ball cage: fabrication and characterization. $23^{\text {rd }}$ IEEE International Conference on Micro Electro Mechanical Systems, MEMS 2010, Hong Kong, pp. 687-690.

Huang, M-S., Hsu, H-C., 2009. Effect of backbone polymer on properties of 316L stainless steel MIM compact. J. Mater. Process. Tech., 209, 5527-5535.

Imgrund, Ph., Rota, A., Simchi, A., 2008. Microinjection moulding of 316L/17-4PH and 316L/Fe powders for fabrication of magnetic-nonmagnetic bimetals. J. Mater. Process. Tech., 200, 259-264.

Kim, K., Liu, X., Zhang, Y., Sun, Y., 2008. MicroNewton force-controlled manipulation of biomaterials using a monolithic MEMS microgripper with two-axis force feedback. 2008 IEEE International Conference on Robotics and Automation, ICRA 2008, Pasadena, CA. 3100-3105.

Koch, R., Sandoz, W., 1994. Finger joint Prosthesis made of metal. US Patent: 5,290,314.

Kong, X., Barriere, T., Gelin, J.C., 2012. Determination of critical and optimal powder loadings for 316L fine stainless steel feedstocks for micro-powder injection molding. J. Mater. Process. Tech., 212, $2173-2182$.

Leong, T. G., Zarafshar, A. M., Gracias, D. H., 2010. Three-dimensional fabrication at small size scales. Small, 6, 792-806.

Li, S. G., Fu, G., Reading, I., Tor, S. B., Loh, N. H., Chaturvedi, P., Yoon, S. F., Youcef-Toumi, K, 2007. Dimensional variation in production of high-aspect-ratio micro-pillars array by micro powder injection molding. Appl. Phys. A-Mater., 89, 721-728.

Li, Y., Liu, S., Qu, X., Huang, B., 2003. Thermal debinding processing of 316L stainless steel powder injection molding compacts. J. Mater. Process. Tech., 137, 65-69.

Ling, Z., Lian, K., 2007. In situ fabrication of SU-8 movable parts by using PAG-diluted SU-8 as the sacrificial layer. Microsyst. Technol., 13, 253-257.

Liu, L., Loh, N. H., Tay, B. Y., Tor, S. B., Murakoshi, Y., Maeda, R., 2005. Mixing and characterisation of 316L stainless steel feedstock for micro powder injection molding. Mater. Charact., 54, 230-238. on surface roughness in micro powder injection molding. Mater. Lett., 61, 809-812. metal microstructures. Mater. Sci. Forum, 426-432, 4289-4294. 

replacement system. J. Hand Surg.-Eur. Vol., 36E, 599-604.

Nishiyabu, K., Kanoko, Y., Tanaka, S., 2007. Innovations in micro metal injection molding process by lost form technology. Mater. Sci. Forum, 534-536, 369-372.

Omar, M. A., Ibrahim, R., Sidik, M. I., Mustapha, M., Mohamad, M., 2003. Rapid debinding of 316L stainless steel injection moulded component. J. Mater. Process. Tech., 140, 397-400.

Piotter, V., Finnah, G., Oerlygsson, G., Ruprecht, R., Haußelt, J., 2005. Special variants and simulation of micro injection moulding. Injection Moulding 2005: Collected Papers of the 5th International Conference, Copenhagen, Denmark, 1-2 March 2005. ceramic parts fabricated by microminiature powder injection molding. Int. J. Powder Metall., 46, 21-

Piotter, V., Mueller, T., Plewa, K., Ritzhaupt-Kleissl, H.-J., Ruh, A., Hausselt, J., 2010b. One- and twocomponent micro powder injection moulding derived from thermoplastic microreplication. Plast. Rubber Compos., 39, 287-292.

Pister, K. S. J., Judy, M. W., Burgett, S. R., Fearing, R. S., 1992. Microfabricated hinges. Sensor Actuat. A-Phys., 33, 249-256.

Rafi Raza, M., Ahmad, F., Omar, M. A., German, R. M., 2012. Effects of cooling rate on mechanical properties and corrosion resistance of vacuum sintered powder injection molded 316L stainless steel.

Rota, A., 2002. New features in material issues for metallic micro components by MIM. Proc. PM2TEC pp 10/49-/57

Ruh, A., Dieckmann, A.-M., Heldele, R., Piotter, V., Ruprecht, R., Munzinger, C., et al. (2008). Production of two-material micro-assemblies by two-component powder injection molding and sinter-joining. Microsyst. Technol., 14, 1805-1811. improvement and injection moulding tool design on the movability of sintered two-component micro parts. Microsyst. Technol., 16, 1989-1994. 
578 Samanta, S. K., Chattopadhyay, H., Godkhindi, M. M., 2011. Thermo-physical characterization of binder and feedstock for single and multiphase flow of PIM 316L feedstock. J. Mater. Process. Tech., 211, 2114- 2122.

581 Seidemann, V., Rabe, J., Feldmann, M., Büttgenbach, S., 2002. SU8-micromechanical structures with in situ fabricated movable parts. Microsyst. Technol., 8, 348-350.

583 Tay, B. Y., Liu, L., Loh, N. H., Tor, S. B., Murakoshi, Y., Maeda, R., 2005. Surface roughness of

584 microstructured component fabricated by $\mu$ MIM. Mat. Sci. Eng. A-Struct., 396, 311-319.

585 Waits, C. M., Geil, B., Ghodssi, R.,2007. Encapsulated ball bearings for rotary micro machines. $\underline{\text { J. }}$

$586 \quad$ Micromech. Microeng., 17, S224-S229.

587 Yang, Y., Su, X., Wang, D., Chen, Y., 2011. Rapid fabrication of metallic mechanism joints by selective 588 laser melting. P. I. Mech. Eng. B-J. Eng., 225, 2249-2256.

589 Zhu, Z., Hassanin, H., Jiang, K., 2010. A soft moulding process for manufacture of net-shape ceramic microcomponents. Int. J. Adv. Manuf. Tech., 47, 147-152. 
2013-09-09

\section{Creating movable interfaces by micro-powder injection moulding}

Attia, Usama M.

Elsevier

U.M. Attia, M. Hauata, I. Walton, D. Annicchiarico, J.R. Alcock, Creating movable interfaces by micro-powder injection moulding, Journal of Materials Processing Technology, Volume 214, Issue 2, February 2014, Pages 295-303 http://dx.doi.org/10.1016/j.jmatprotec.2013.09.012.

Downloaded from Cranfield Library Services E-Repository 